\title{
Gluten-Free Snacks Based on Brown Rice and Amaranth Flour with Incorporation of Cactus Pear Peel Powder: Physical, Nutritional, and Sensorial Properties
}

\author{
Dayanne Vigo Miranda, ${ }^{1}$ Meliza Lindsay Rojas, ${ }^{2}$ Sandra Pagador, ${ }^{1}$ Leslie Lescano, ${ }^{3}$ \\ Jesús Sanchez-Gonzalez, ${ }^{3}$ and Guillermo Linares $\mathbb{D}^{3}$ \\ ${ }^{1}$ School of Agroindustrial Engineering, Universidad César Vallejo (UCV), AV. Víctor Larco Herrera 13009, Trujillo, Peru \\ ${ }^{2}$ Department of Agri-food Industry, Food and Nutrition (LAN), Luiz de Queiroz College of Agriculture (ESALQ), \\ University of São Paulo (USP), AV. Padua dias 11, Piracicaba, SP, Brazil \\ ${ }^{3}$ School of Agroindustrial Engineering, Universidad Nacional de Trujillo (UNT), Av. Juan Pablo II s/n, Trujillo, Peru
}

Correspondence should be addressed to Guillermo Linares; glinares@unitru.edu.pe

Received 20 July 2018; Revised 4 October 2018; Accepted 23 October 2018; Published 29 October 2018

Academic Editor: Vita Di Stefano

Copyright (C) 2018 Dayanne Vigo Miranda et al. This is an open access article distributed under the Creative Commons Attribution License, which permits unrestricted use, distribution, and reproduction in any medium, provided the original work is properly cited.

\begin{abstract}
An agroindustrial by-product (cactus pear peel) and whole grains flour (brown rice and amaranth) were used to present a glutenfree snack proposal. The effect of 5\% (F1), 7\% (F2), and 10\% (F3) substitution of brown-rice flour for yellow cactus pear peel powder (Opuntia ficus-indica) on the snack physical, sensorial, and nutritional properties was evaluated. In addition, 20\% of amaranth flour (Amaranthus caudatus) was used for all formulations. As the percentage of substitution increased, the a* value increased, while the $\mathrm{L} *$ decreased. The control snacks presented higher hardness, while the snacks with $10 \%$ substitution presented a greater crispness. The sensorial properties (overall liking, colour, crispness, and oiliness) reported that the samples containing cactus pear peel powder were the most accepted. The fat content decreased as the substitution percentage increased. The F3 formulation presented the best physical and sensorial properties and when compared with other commercial snack brands, it presented low fat and an adequate protein and fibre content. Therefore, snacks based on brown rice, amaranth, and cactus pear by-product could be considered as a good option of gluten-free product, contributing to reducing the lack of gluten-free products on the markets.
\end{abstract}

\section{Introduction}

The food industry has more and more challenges to meet current needs and consumer demands. On one hand, it offers healthy and safe foods with pleasant taste, appearance, and affordable cost. On the other hand, there is an environmental concern, where environment-friendly processes and agroindustrial by-products use are desired. Therefore, food scientists and engineers have the task of providing different alternatives considering the quality of the process, the product, and the special needs of the population, such as diseases that involve an immune response to any dietary compound, such as celiac disease.

Based on studies from United States [1] and Europe, the celiac disease incidence is about $1 \%$ of the world population; however, $85 \%$ to $90 \%$ of this has not been diagnosed nor treated [2]. The pathophysiology of celiac disease involves both the innate and adaptive immune response to dietary gluten. It is characterized by a permanent intolerance for gluten proteins present in dietary wheat, rye, and barley $[3,4]$. It was reported that patients (about $50 \%)$ present atypical forms of celiac disease related to dermatitis herpetiformis, iron-deficiency anemia, neurologic problems, and others [5]. It was also reported that gluten causes gastrointestinal symptoms in subjects without celiac disease [6], such as irritable bowel syndrome [7]. Therefore, despite the growing number of people with celiac disease and other gluten-sensitivity-related problems [8], there is still a lack of gluten-free products on the market. 
Although a gluten-free diet is effective in most patients, many patients find it unsatisfactory. This diet can be burdensome and can limit the quality of life; it is expensive, with bread and pasta substitutes costing substantially more than their gluten-containing counterparts [8]. In fact, some products based on oat, starches, hydrocolloids, gums, pulses ingredients, and fibre [9-11] were used to produce gluten-free products. Therefore, a greater variety of gluten-free products with good physical, nutritional, and sensory characteristics are required, in addition to affordable prices.

One way to produce quality food products with low prices, besides reducing the environmental impact, is the use of agroindustrial by-products. In fruit processing, around $70 \%$ of the raw material, such as peel and seeds, is considered waste. Peels are promising fruit by-products because of their high content of insoluble and dietary fibre, pectin, and fructooligosaccharides, as well as phenolic compounds, proteins, minerals, and vitamins. In addition to the favourable physical or nutritional properties, the use of agroindustrial by-products as food additives or supplements has gained increasing interest because their recovery may be economically attractive [12-15].

In this work, the use of an agroindustrial by-product was proposed, that is, the use of cactus pear peels. Cactus pear production using conventional system is around 3080 tonnes ha ${ }^{-1}$ and intensive system 179-263 tonnes ha ${ }^{-1}$ [16]. Cactus pear peel is the major by-product that represents $38 \%$ of fruit weight, resulting from fresh consumption or juice production [17]. The cactus pear peels were used as fibre source; the fibre content of cactus pear peel powder varies from $39 \%$ [18] to $64 \%$ [12]. On the other hand, there is a growing interest in adding value to Andean crops, so amaranth was used, an Andean grain that presents more than $13 \%$ of protein [19]. Additionally, brown-rice flour as the flour basis was used. In fact, the rice flour is gaining popularity as the alternative of wheat flour [20]. Some of the main nutritional compounds of cactus pear peel powder, amaranth flour, and brown-rice flour are presented in Table 1.

Therefore, the objective of the present work was to evaluate the effect of brown-rice flour substitution (5\%,7\%, and $10 \%$ ) with yellow cactus pear peel powder on the physical (instrumental colour, texture, and moisture content), sensory (overall liking and attributes of colour, texture, and oiliness), and nutritional properties (fat, protein, and fibre content) of gluten-free snacks with addition of amaranth flour (20\%).

\section{Materials and Methods}

\subsection{Raw Materials}

2.1.1. Brown-Rice and Amaranth Flour. The brown rice and amaranth were free of impurities and had low moisture content (amaranth grain: $10.47 \%$; brown rice: $8.21 \%$ ). The whole grains of rice and amaranth were ground in an electric mill for grains and the resulting product was sieved in a mesh $\mathrm{N}^{\circ} 140(0.105 \mathrm{~mm})$ until obtaining a fine flour. The obtained flour was stored in hermetic containers at room temperature.
2.1.2. Yellow Cactus Pear Peel Powder. Fresh yellow cactus pears (commonly known in Peru as tuna) produced in Santiago de Chuco-La Libertad were obtained from a local market (Trujillo, Peru). The fruits without damage were washed and sanitized. The peels were removed using a knife and cut in pieces of $2 \mathrm{~cm}^{2}$. The peels presented a $\mathrm{pH}$ of $5.73 \pm$ 0.12 and ${ }^{\circ}$ Brix of $8.90 \pm 0.10$. Subsequently, the cut peels were dried at $70^{\circ} \mathrm{C}$ for $24 \mathrm{~h}$ using an oven (BOX 1720, MEMMERT, Germany) until reaching $1.84 \mathrm{~g}$ water $/ 100 \mathrm{~g}$ dry matter.

Dried peels were ground using the same grain electric mill and then sieved using a mesh $\mathrm{N}^{\circ} 100(0.149 \mathrm{~mm})$ until obtaining a fine powder. The obtained powder was stored in hermetic containers at room temperature.

2.2. Formulation and Preparation of Snacks. The snacks were prepared according to the formulations shown in Table 2. The control snacks were prepared with $20 \%$ of amaranth flour and $80 \%$ of brown-rice flour. The amaranth flour percent $(20 \%)$ was maintained constant for all formulations. Formulations 1,2 , and 3 were prepared by substitution of brown-rice flour with cactus pear peel powder. Substitutions were conducted based on $5 \%, 7 \%$, and $10 \%$ of the weight of the brown-rice flour.

The snacks were prepared for each formulation in the same manner. Firstly, according to the type of formulation (Table 2), the cactus pear peel powder, the amaranth flour, and the brown-rice flour were mixed. For each $100 \mathrm{~g}$ of mixture, 5 $\mathrm{g}$ of salt, $70 \mathrm{~mL}$ of water, and $40 \mathrm{~g}$ of butter were added (this quantity provided a texture appropriate to the dough, which allowed future handling without rupture). The mixture was then kneaded to form a smooth dough. The dough was steam precooked for $20 \mathrm{~min}$. Subsequently, the dough was cooled at room temperature, followed by sheeting until reaching a final thickness of $1 \mathrm{~mm}$. The sheets of dough were then cut into circles using a mould of $4 \mathrm{~cm}$ diameter. Finally, they were fried in sunflower oil at $170^{\circ} \mathrm{C}$ for $5 \mathrm{~s}$; the obtained snacks are shown in Figure 1. The snacks were stored in hermetic containers in a cool and dry place for posterior analyses. Four repetitions of each formulation were performed.

\subsection{Physical Properties}

2.3.1. Instrumental Colour. The instrumental colour of fried snacks was measured on the snack surface according to the method described by Mir et al. [22], using a spectrophotometer (Konica Minolta CM-5, Japan). The CIE (Commission Internationale d'Eclairage) colour scale was used, where parameters of $\mathrm{L}^{*}$ (lightness), $\mathrm{a}^{*}$ (green to red), and $\mathrm{b}^{*}$ (blue to yellow) were measured.

2.3.2. Instrumental Texture. The instrumental texture of fried snacks was evaluated according to Alam et al. [23] by a compressive test using a texturometer (TA-HDplus, UK). A stainless-steel spherical probe $(\mathrm{P} / 0.25 \mathrm{~s})$ was inserted at a constant rate of $1 \mathrm{~mm} / \mathrm{s}$ over a distance of $3 \mathrm{~mm}$ until it cracked the snack. The maximum compression force considered as the highest point of the force $(\mathrm{N})$ versus time (s) curve was used for describing the sample texture (in terms of 
TABLE 1: Main nutritional compounds of cactus pear peel powder, amaranth flour, and brown rice flour.

\begin{tabular}{ccccc}
\hline \multicolumn{2}{c}{ Compound (x 100g of product) } & Cactus pear peel powder ${ }^{(1)(2)}$ & Amaranth flour $^{(3)}$ & Brown rice flour $^{(3)}$ \\
\hline Protein & $\mathrm{g}$ & 5.71 & 13.33 & 7.23 \\
Total Fat & $\mathrm{g}$ & 3.33 & 6.67 & 2.78 \\
Fibre, total dietary & $\mathrm{g}$ & 64.15 & 11.10 & 4.60 \\
Carbohydrates & $\mathrm{g}$ & 71.84 & 66.67 & 76.48 \\
Total carotenoids & $\mathrm{mg}$ & 217.11 & $\mathrm{Nr}$ & $\mathrm{nr}$ \\
Calcium & $\mathrm{mg}$ & $\mathrm{Nr}$ & 178.00 & 11 \\
Iron & $\mathrm{mg}$ & $\mathrm{Nr}$ & 7.20 & 1.98 \\
\hline
\end{tabular}

nr: nonreported. Mean values obtained from ${ }^{(1)}$ Elhassaneen and Ragab [18], ${ }^{(2)}$ Diaz-Vela and Totosaus [12], and ${ }^{(3)}$ USDA [21].

TABLE 2: Snacks formulation.

\begin{tabular}{lccc}
\hline Formulation & Cactus pear peel powder (\%) & Amaranth flour (\%) & Brown rice flour (\%) \\
\hline Control & - & 20 & 80 \\
Formulation 1 (F1) & 5 & 20 & 75 \\
Formulation 2 (F2) & 7 & 20 & 73 \\
Formulation 3 (F3) & 10 & 20 & 70 \\
\hline
\end{tabular}

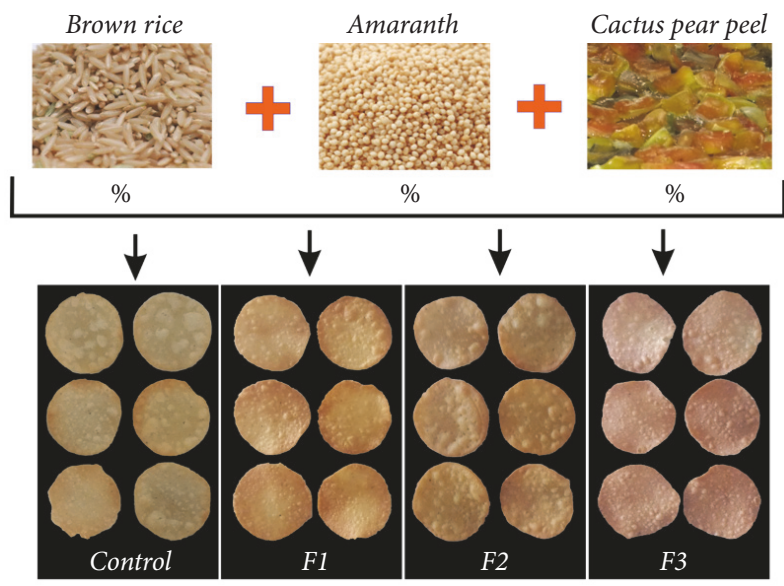

FIGURE 1: Snacks obtained with the different used formulations.

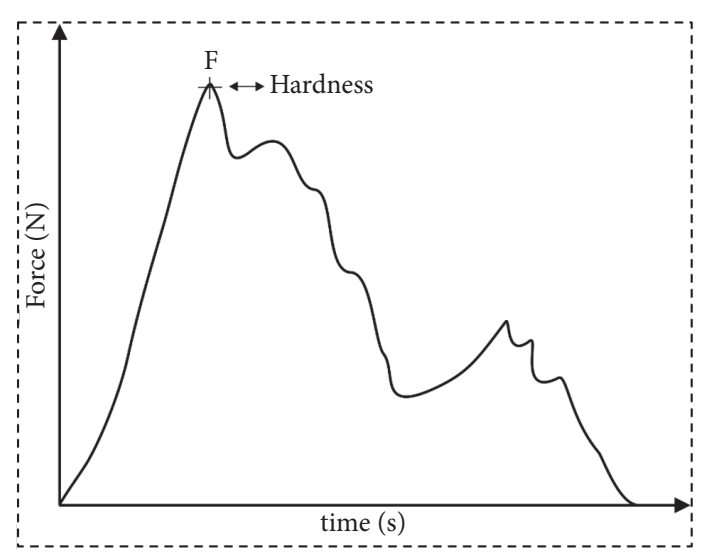

FIGURE 2: Typical curve of force $(\mathrm{N})$ versus time (s) showing the maximum compression force used for describing the snack texture. hardness) (Figure 2). The analysis was performed in triplicate for each formulation replicate, that is, 12 texture readings for each formulation.

2.4. Moisture Content. The moisture content of the raw materials and snacks was measured by drying the crushed snacks samples at $105^{\circ} \mathrm{C}$ using a moisture analyzer (MX50, A\&D Company, Tokyo, Japan); for this a HI (high) accuracy mode was selected. The moisture measurement was completed when the drying rate was lower than $0.02 \% / \mathrm{min}$.

2.5. Sensorial Properties. The snack sensorial properties were evaluated according to Ho and Abdul Latif [24] and Cruz et al.[25], with some modifications. A total of 97 untrained panellists (63\% male and 37\% female, age range: $18-25$ years) were recruited for the sensory analysis. All participants were informed in an orientation session about the objectives and the use of the scale and signed an ethics consent form. The coded samples were provided to each panellist in a monadic sequential order. For each snack formulation, using a 7-point structured hedonic scale, consumers evaluated the overall liking, the colour (defined as the intensity of colour present on the surface of the snack; it varied from (1) very pale to (7) Very dark), the oiliness (defined as the taste and sensation of oil in snacks; it varied from (1) any oiliness to (7) very intense oiliness), and crispiness (defined as the degree of "crunch" or sound produced when the snack is bitten; it varied from (1) very slight sound to (7) very intense sound).

\subsection{Nutritional Properties}

2.6.1. Fat Content. The fat percentage $(\% \mathrm{~F})$ of the snacks was determined using the Soxhlet extraction method, AOAC Method $N^{\circ} 922.06$ [26]. After frying, the samples were dried, triturated, and placed inside a thick filter paper thimble, which was placed into the Soxhlet equipment for fat extraction using a combination of analytical grade ethyl ether and 
TABLE 3: Instrumental colour parameters in the different formulations of snacks*.

\begin{tabular}{lcccc}
\hline Colour parameters & \multicolumn{2}{c}{ Formulations } & F2 & F3 \\
\hline $\mathrm{L} *$ & Control & F1 & $34.41 \pm 0.29^{\mathrm{b}}$ & $32.11 \pm 0.53^{\mathrm{c}}$ \\
$\mathrm{a} *$ & $50.17 \pm 2.22^{\mathrm{a}}$ & $43.29 \pm 1.24^{\mathrm{b}}$ & $6.72 \pm 0.42^{\mathrm{a}}$ & $10.37 \pm 0.95^{\mathrm{b}}$ \\
$\mathrm{b} *$ & $4.55 \pm 0.82^{\mathrm{a}}$ & $5.94 \pm 0.93^{\mathrm{a}}$ & $21.80 \pm 0.25^{\mathrm{a}}$ & $22.80 \pm 0.73^{\mathrm{a}}$ \\
$\Delta \mathrm{E}$ & $22.21 \pm 1.59^{\mathrm{a}}$ & $23.71 \pm 0.64^{\mathrm{b}}$ & $15.96 \pm 1.98^{\mathrm{b}}$ & $19.10 \pm 2.23^{\mathrm{b}}$ \\
\hline
\end{tabular}

$*$ mean \pm standard deviation. Differences among letters indicate significant differences among formulations $(\alpha=5 \%)$.

petroleum ether (1:1) (Merck, Darmstadt). The determination was performed in triplicate for each formulation replicate.

After having carried out the physical, sensorial, and fat content analyses, the formulation that obtained the best properties and sensory acceptance was selected. For the snacks processed using this formulation, the amounts of protein and fibre were determined. In addition, the fat, protein, and fibre composition of the snacks made in this study was compared with those quantities reported for some brands of commercial snacks. The used brands were Los cuates (Karinto S.A.C, Lima, Peru), Lay's ${ }^{\circledR}$ classic, and Doritos nacho cheese flavoured (Frito-Lay Inc., Texas, USA) from PepsiCo Inc. Company.

2.6.2. Protein Content. The proteins were determined using the Kjeldahl digestion and distillation method, According to the methodology described by the AOAC method $\mathrm{N}^{\circ} 920.87$ [27].

2.6.3. Crude Fibre Content. The crude fibre content was determined according to the methodology described by the AOAC method $N^{\circ} 978.10$ [28].

2.7. Statistical Analysis. Data were analyzed using the Statgraphics Centurion (StatSoft, USA) software. Analyses were performed through analysis of variance (ANOVA) at $95 \%$ confidence $(p<0.05)$, followed by Duncan test to identify significant differences among treatments.

\section{Results and Discussion}

\subsection{Physical Properties}

3.1.1. Instrumental Colour. In snacks, the colour is one of the most important attributes judged by the consumer. Visually, as shown in Figure 1, the snacks presented differences in colour; this was evidenced objectively through the instrumental measurement. Table 3 shows the instrumental colour parameters value. The $\mathrm{L} *$ parameter (lightness) decreased as the percentage of cactus peel powder increased. Therefore, less lightness was detected in formulations with the highest percentage of cactus pear peel powder (F3). Contrary to the $L *$ values, the a* values increased as the percentage of brown-rice flour substitution increased, the highest a* value being that for the F3 formulation. The values of $\mathrm{b} *$ were kept similar in the F2 and F3 samples, with a slight increase in F1 when compared to the control. Lastly, the total colour difference $(\Delta E)$ increased as the percentage of cactus pear powder increased.

In Table 3 , it is observed that the lightness value $(\mathrm{L} *)$ decreased as the percentage of substitution of brown-rice flour increased. This result makes sense because the cactus pear peel powder used contain pigments, in addition to other reactions that occur with the temperature increase during frying. In fact, the betalain and chlorophyll are pigments of the cactus pear peel powder, which are susceptible to the temperature, $\mathrm{pH}$, and light [29]. These pigments generate compounds of dark brown colouration that decreased the lightness. Additionally, previous studies attributed the changes in $\mathrm{L} *$ to reducing sugars content present in the raw material. If this content is low, golden snacks will be obtained; however, if the content of reducing sugars is excessive, it will cause a deep brown colouration in the final product decreasing the lightness [30].

The a* parameter (from green $(-)$ to red $(+)$ ) is used to determine the optimal frying point of fried products. In this work, the value of $\mathrm{a} *$ increased as the percentage of brownrice flour substitution was increased (Table 3 ). That is, the colour of the samples was approximated to a red colour as the percentage of cactus pear powder increased. Meanwhile, in the case of $\mathrm{b} *$ parameter (from blue (-) to yellow $(+)$ ), for all samples obtained similar and positive results, comparable results were reported by Heredia and Castelló [31]. The obtained results could be due to the used variety of cactus pear, where peel powder was yellow; therefore it conferred to the formulations a yellowish colour.

Finally, all variations in the $\mathrm{L} *, \mathrm{a} *$, and $\mathrm{b} *$ parameters for each formulation impacted the total colour difference $(\Delta \mathrm{E})$ (Table 3 ). As stated above, both the raw material composition and the reactions that occur during processing contributed to this colour differences. For example, the different chemical reactions such as caramelization (Maillard reaction), nonenzymatic reactions, and structural changes were accelerated by the high temperatures during the frying process [32].

3.1.2. Texture. The texture is another important sensory attribute for the fried snacks acceptance [33]. Usually, the instrumental texture in foods like snacks is determined through a compression test, where the force-displacement curves are obtained (Figure 2). The curves usually have an irregular appearance with several fracture events. This behaviour is observed in crispy foods [34]. The first important drop of force is associated with a major structural breakdown; in this region, the probe mainly deforms the sample [35]. The 


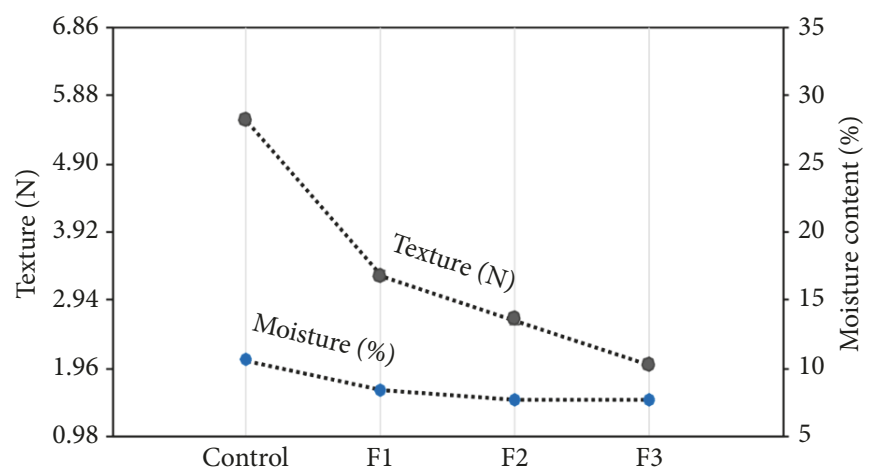

Figure 3: Texture (force $(\mathrm{N})$ ) and moisture content (\%) for each snack formulation.

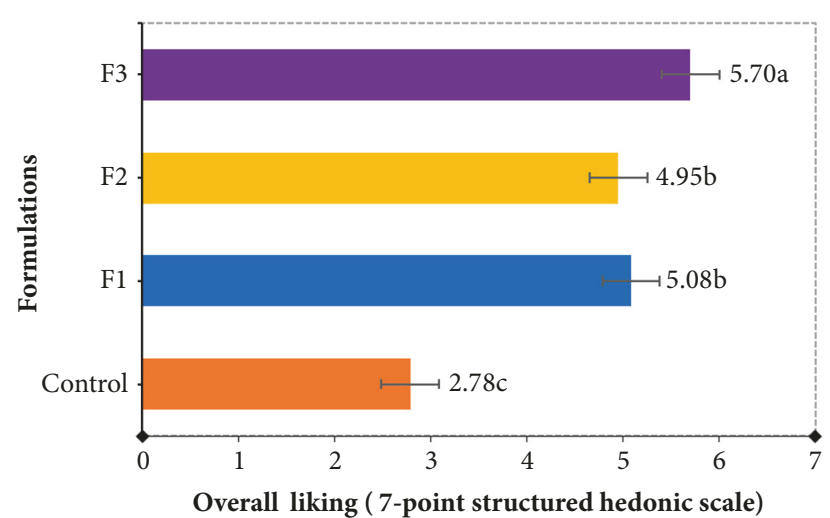

FIGURE 4: Average of the overall liking scores of each formulation, using a 7-point hedonic scale.

texture of the snacks was expressed as the maximum force needed to break the snack.

Significant differences $(p<0.05)$ among the texture of all the samples were observed. The force needed to break the snack decreases as the percentage of substitution of brown-rice flour increases (Figure 3). The control samples obtained the highest value $(5.52 \pm 0.03 \mathrm{~N})$, while the F3 $(10 \%$ substitution) samples obtained the lower value of force (2.02 $\pm 0.02 \mathrm{~N}$ ). Additionally, it was observed that the moisture content (\%) is directly proportional to the strength needed to break the snack (Figure 3).

According to Kita and Lisińska [36], samples with very low solid content and high fat content are less crisp and stickier. This occurred with the control samples, which showed high moisture (Figure 3 ) and fat content (Table 5). In addition, there are several factors influencing texture properties such as raw material composition, frying temperature, and oil type [37]. In this work, the temperature and time of frying and the oil type were the same; therefore, probably the observed differences on the snack properties were due to their different composition. For example, the control snacks contained a high quantity of brown-rice flour. The brown-rice flour, among others, contains fibre and starch. According to Pacheco-Delahaye [38], during frying, the starch contributes to the crust formation, causing a hard product. As observed, the control snacks presented the higher hardness value. In contrast, the F3 samples presented lower hardness results, indicating that they were more fragile or crisp.

3.2. Moisture Content. Figure 3 shows the moisture content (\%) tendency obtained regarding each formulation. As observed, the force (N) and moisture content (\%) showed direct dependency on the snack composition, which decreased as the percentage of brown-rice flour substitution increased. Therefore, the control snacks showed the greater hardness and moisture (\%), while the F3 (10\% cactus pear peel powder) showed the lowest moisture content with most crispy texture.

Different variables act simultaneously and influence the obtained results [39]. According to van Koerten and Schutyser [40] a lower moisture content results in an increased porosity. The increased porosity decreases the breaking resistance, which in turn results in a crispier behaviour after frying. This could have occurred when the percentage of brown-rice flour substitution increased, where the snacks porosity probably increased, resulting in the observed behaviour.

The observed moisture content could be attributed to the rice flour composition, which contributed to the crust formation. In other products that also contain starch, such as potato chips, the crust formation was reported [41]. Therefore, probably the snacks that contained more quantity of brown-rice flour (as in the case of control snacks) formed rapidly crust increasing the external resistances to water exit. Consequently, the water inside the snack remained trapped, increasing the moisture content.

3.3. Sensorial Properties. The analysis of variance (ANOVA) showed no significant effect on the consumers. However, there was a significant effect for the snacks formulation $(p<$ 0.05).

Figure 4 shows the overall liking for each snack formulation. The snacks that were most liked were those prepared using the formulations F1, F2, and F3; these snacks have an average acceptance of more than 5 on a hedonic scale of 7 points. Therefore, the three formulations mentioned above have a great possibility of being accepted by consumers. 
TABLE 4: Results of the sensory attributes (colour, crispiness, and oiliness) evaluated for the different snacks formulation*.

\begin{tabular}{lcccc}
\hline Attributes & Control & Formulation & F2 & F3 \\
\hline Colour & $3.15 \pm 1.12^{\mathrm{a}}$ & $4.21 \pm 1.31^{\mathrm{b}}$ & $5.43 \pm 0.89^{\mathrm{c}}$ & $5.79 \pm 0.82^{\mathrm{d}}$ \\
Crispiness & $2.43 \pm 1.29^{\mathrm{a}}$ & $4.58 \pm 1.26^{\mathrm{b}}$ & $4.9 \pm 1.10^{\mathrm{c}}$ & $5.10 \pm 1.29^{\mathrm{c}}$ \\
Oiliness & $4.19 \pm 1.47^{\mathrm{a}}$ & $3.7 \pm 1.23^{\mathrm{b}}$ & $3.94 \pm 1.31^{\mathrm{b}}$ & \\
\hline
\end{tabular}

$*$ mean \pm standard deviation. Differences among letters indicate significant differences among formulations $(\alpha=5 \%)$.

TABLE 5: Fat content (\%) for the snacks obtained with different formulations*.

\begin{tabular}{lc}
\hline Formulations & Fat content $(\%)$ \\
\hline Control & $31.75 \pm 0.01^{\mathrm{a}}$ \\
F1 & $30.08 \pm 0.01^{\mathrm{b}}$ \\
F2 & $30.41 \pm 0.01^{\mathrm{b}}$ \\
F3 & $26.89 \pm 0.13^{\mathrm{c}}$ \\
\hline
\end{tabular}

* mean \pm standard deviation. Differences among letters indicate significant differences among formulations $(\alpha=5 \%)$.

However, among these three formulations, the F3 formulation has the greatest acceptance. In contrast, the sample with the lowest acceptance by consumers was the control sample. Therefore, it can be inferred that the snacks without the addition of cactus pear peel powder presented low acceptance values.

Regarding the specific sensory attributes of snacks (colour, crispiness, and oiliness) (Table 4), the colour attribute scores were among "slightly pale" and "moderately dark" colour. It was observed that the colour score increased as the percentage of cactus pear peel powder increased. That is, the F3 formulation obtained the highest colour intensity punctuation; in fact, it was evidenced instrumentally where these samples showed higher a* and lower $\mathrm{L} *$ values. For the crispiness attribute, scores between 2.4 and 5.1 were obtained, which are equivalent in the hedonic scale to "mildly slight" and "slightly intense." In this regard, the snacks prepared with the F3 formulation were the crispiest. Furthermore, significant differences were found in the oiliness attribute, where the snacks of the F3 formulation showed fewer scores, with an average score of 2.97. It means that these snacks presented less taste and an oily sensation. In contrast, the control sample obtained the highest oiliness score of 4.19, equivalent to "slightly intense." The oiliness score agreed with what is reported in Table 5, where the F3 and control samples showed the lowest and highest fat percentage, respectively.

\subsection{Nutritional Properties}

3.4.1. Fat Content (\%). The fat of fried snacks is an important component, which affects their flavour, texture, and shelf life. In the last years, the demand for healthy products, such as low-fat products, has been increasing [42]. Therefore, different studies were performed to obtain low-fat products, for example, by applying pretreatments $[25,43]$. In this study, the use of $10 \%$ cactus pear peel powder (F3) allowed obtaining snacks with the lowest fat percentage, while the highest percentage of fat was obtained for control snacks (Table 5).

In addition to the fat content of the raw materials and the fat used in the elaboration of the dough, during deep fat frying, there are coupled heat and mass transfer phenomena. During the mass transfer moisture loss and oil uptake simultaneously occur [25].

The mass transfer (moisture loss and oil uptake) is affected by the food-related properties (such as structure, composition, porosity, vapour pressure, and surface roughness) and by the process conditions (such as temperature, frying time, and type of used oil) [36, 43-48]. In fried products, the highest percentage of oil absorbed is on the surface, where the structure of the formed crust is a key factor $[41,49]$.

In fact, the control snacks showed the greater hardness and moisture (\%) (Figure 3) and a high fat content (Table 5), while F3 (10\% cactus pear peel powder) showed the lowest fat and moisture content with most crispy texture. Therefore, the high fat and moisture content observed in the control samples could be attributed to the crust formation. The oil content of the crust was higher than that of the core regions [41]. Probably the control snacks that contained more quantity of brown-rice flour formed rapidly crust storing more oil, thus increasing $\% \mathrm{~F}$.

3.4.2. Protein and Fibre Content. Under the process conditions, F3 formulation allowed obtaining snacks with the best physical and sensory properties (low fat content, adequate colour and hardness, and greater overall acceptability). Therefore, for this formulation, analyses of proteins and fibre content were performed and compared with other brands typically found in markets (Table 6).

As shown in Table 6, the F3 sample presented lower fat content compared to the other brands; in addition, it contained a slightly higher percentage of proteins (7.22\%). This can be due to the protein content of the used raw materials. However, apparently, it had a lower fibre content $(2.13 \%)$; this is because the fibre content value in this work was reported as crude fibre and the value reported in the label of commercial snacks corresponds at the dietary fibre content. When the crude fibre method is used, the dietary fibre (DF) content is significantly underestimated, since a large part of the hemicellulose and lignin is dissolved, as well as varying amounts of cellulose and all the soluble fibres. The DF values are generally 3 to 5 times higher than the crude fibre [50,51]. Therefore, the F3 formulation could present a high value of dietary fibre. Although not evidenced, this possibility is 
TABLE 6: Nutritional comparison of fried snacks with other brands.

\begin{tabular}{lcccc}
\hline Compound & F3 & Los Cuates* & $\begin{array}{c}\text { Composition (\%) } \\
\text { Lay's }{ }^{\circledR} \text { Classic* }\end{array}$ & Doritos Nacho cheese flavoured $*$ \\
\hline Fat & 26.89 & 36.73 & 35.71 & 28.57 \\
Protein & 7.22 & 7.14 & 7.14 & 7.14 \\
Fibre & $2.13(\mathrm{CF})$ & $3.57(\mathrm{DF})$ & $3.57(\mathrm{DF})$ & $3.57(\mathrm{DF})$ \\
\hline
\end{tabular}

* Data obtained from nutrition facts reported in the product label. CF: crude fibre; DF: dietary fibre.

supported by the types of flours that were used, both rice and amaranth, which were of an integral type. Further, previous studies reported that cactus pear peel powder has a $64.15 \%$ total dietary fibre (Table 1): $33.48 \%$ insoluble and $30.67 \%$ soluble [12].

\section{Conclusions}

The substitution of brown-rice flour with cactus pear peel powder directly influenced the physical properties of the snacks. At a higher percentage of substitution, the a* colour parameter value increased, while the lightness $(\mathrm{L} *)$ decreased with smaller variations in the $\mathrm{b} *$ value. In addition, the instrumental texture values decreased as the percentage of substitution increased; the control snacks presented higher hardness values, while the snacks with the higher percentage of substitution (such as F3) had lower hardness values, suggesting a greater crispness. The evaluation of sensorial properties reported that the samples containing cactus pear peel powder were the most accepted. For the specific sensory attributes of colour, texture, and oiliness, it was obtained that the higher percentage of substitution obtained better values of acceptance. The fat content decreased as the substitution percentage increased. Therefore, the F3 formulation presented the best physical and sensorial properties and low fat content. Additionally, when compared with other commercial brands, the F3 snacks elaborated in this study presented an adequate protein and fibre content. Therefore, the elaboration of snacks is a good proposal to exploit the use of agroindustrial byproducts and provide gluten-free products.

\section{Data Availability}

The experimental data used to support the findings of this study are available from the corresponding author upon request.

\section{Conflicts of Interest}

The authors declare that there are no conflicts of interest regarding the publication of this paper.

\section{Acknowledgments}

The authors are grateful to the Laboratory of Process Engineering, Faculty of Agricultural Sciences, Universidad Nacional de Trujillo, and to Cienciactiva for the M.L. Rojas Ph.D. (CONCYTEC, Peru; Contract 087-2016-FONDECYT) scholarship from "Consejo Nacional de Ciencia, Tecnología e Innovación Tecnológica."

\section{References}

[1] A. Rubio-Tapia, J. F. Ludvigsson, T. L. Brantner, J. A. Murray, and J. Everhart, "1037 The Prevalence of Celiac Disease in the United States," Gastroenterology, vol. 142, no. 5, pp. S-181-S-182, 2012.

[2] S. Guandalini and A. Assiri, "Celiac disease: A review," JAMA Pediatrics, vol. 168, no. 3, pp. 272-278, 2014.

[3] V. M. Wolters and C. Wijmenga, "Genetic background of celiac disease and its clinical implications," American Journal of Gastroenterology, vol. 103, no. 1, pp. 190-195, 2008.

[4] C. Catassi, I.-M. Rätsch, E. Fabiani et al., "Coeliac disease in the year 2000: exploring the iceberg," The Lancet, vol. 343, no. 8891, pp. 200-203, 1994.

[5] A. Fasano and C. Catassi, "Current approaches to diagnosis and treatment of celiac disease: an evolving spectrum," Gastroenterology, vol. 120, no. 3, pp. 636-651, 2001.

[6] J. R. Biesiekierski, E. D. Newnham, P. M. Irving et al., "Gluten Causes gastrointestinal symptoms in subjects without celiac disease: a double-blind randomized placebo-controlled trial," American Journal of Gastroenterology, vol. 106, no. 3, pp. 508514, 2011.

[7] E. F. Verdu, D. Armstrong, and J. A. Murray, "Between celiac disease and irritable bowel syndrome: the 'no man's land' of gluten sensitivity," American Journal of Gastroenterology, vol. 104, no. 6, pp. 1587-1594, 2009.

[8] B. Lebwohl, J. F. Ludvigsson, and P. H. R. Green, "Celiac disease and non-celiac gluten sensitivity," $B M J$, vol. 351, Article ID h4347, 2015.

[9] E. Gallagher, T. R. Gormley, and E. K. Arendt, "Recent advances in the formulation of gluten-free cereal-based products," Trends in Food Science \& Technology, vol. 15, no. 3-4, pp. 143-152, 2004.

[10] M. Peräaho, P. Collin, K. Kaukinen, L. Kekkonen, S. Miettinen, and M. Mäki, "Oats can diversify a gluten-free diet in celiac disease and dermatitis herpetiformis," Journal of the Academy of Nutrition and Dietetics, vol. 104, no. 7, pp. 1148-1150, 2004.

[11] J. J. Han, J. A. M. Janz, and M. Gerlat, "Development of glutenfree cracker snacks using pulse flours and fractions," Food Research International, vol. 43, no. 2, pp. 627-633, 2010.

[12] J. Diaz-Vela, A. Totosaus, A. E. Cruz-Guerrero, and M. De Lourdes Pérez-Chabela, "In vitro evaluation of the fermentation of added-value agroindustrial by-products: Cactus pear (Opuntia ficus-indica L.) peel and pineapple (Ananas comosus) peel as functional ingredients," International Journal of Food Science \& Technology, vol. 48, no. 7, pp. 1460-1467, 2013.

[13] A. Nawirska and M. Kwaśniewska, "Dietary fibre fractions from fruit and vegetable processing waste," Food Chemistry, vol. 91, no. 2, pp. 221-225, 2005. 
[14] V. Oreopoulou and C. Tzia, "Utilization of plant by-products for the recovery of proteins, dietary fibers, antioxidants, and colorants," Utilization of By-Products and Treatment of Waste in the Food Industry, pp. 209-232, 2007.

[15] A. Schieber, F. C. Stintzing, and R. Carle, "By-products of plant food processing as a source of functional compounds-recent developments," Trends in Food Science \& Technology, vol. 12, no. 11, pp. 401-413, 2001.

[16] FAO, Agro-industrial utilization of cactus pear. 2013, Food and Agriculture Organization of the United Nations: Rome.

[17] M. Namir, K. Elzahar, M. F. Ramadan, and K. Allaf, “Cactus pear peel snacks prepared by instant pressure drop texturing: Effect of process variables on bioactive compounds and functional properties," Journal of Food Measurement and Characterization, vol. 11, no. 2, pp. 388-400, 2017.

[18] Y. Elhassaneen, "Improvement of Bioactive Compounds Content and Antioxidant Properties in Crackers with the Incorporation of Prickly Pear and Potato Peels Powder," International Journal of Nutrition and Food Sciences, vol. 5, no. 1, p. 53, 2016.

[19] R. Repo-Carrasco-Valencia, J. K. Hellström, J.-M. Pihlava, and P. H. Mattila, "Flavonoids and other phenolic compounds in Andean indigenous grains: quinoa (Chenopodium quinoa), kañiwa (Chenopodium pallidicaule) and kiwicha (Amaranthus caudatus)," Food Chemistry, vol. 120, no. 1, pp. 128-133, 2010.

[20] G. We et al., Development of rice flour-based puffing snack for early childhood, Food Engineering Progress, 2010.

[21] USDA, USDA Branded Food Products Database,.

[22] S. A. Mir, S. J. D. Bosco, and M. A. Shah, "Technological and nutritional properties of gluten-free snacks based on brown rice and chestnut flour," Journal of the Saudi Society of Agricultural Sciences, 2017.

[23] M. S. Alam, S. Pathania, and A. Sharma, "Optimization of the extrusion process for development of high fibre soybeanrice ready-to-eat snacks using carrot pomace and cauliflower trimmings," LWT- Food Science and Technology, vol. 74, pp. 135$144,2016$.

[24] L.-H. Ho and N. W. b. Abdul Latif, "Nutritional composition, physical properties, and sensory evaluation of cookies prepared from wheat flour and pitaya (Hylocereus undatus) peel flour blends," Cogent Food Agriculture, vol. 2, no. 1, Article ID 1136369, 2016.

[25] G. Cruz, J. P. Cruz-Tirado, K. Delgado et al., "Impact of predrying and frying time on physical properties and sensorial acceptability of fried potato chips," Journal of Food Science and Technology, vol. 55, no. 1, pp. 138-144, 2018.

[26] AOAC, Association of Official Analytical Chemists, in Official methods of analysis: Proximate Analysis and Calculations Crude Fat (CF) Flour. Method No 922.06. 2006: Gaithersburg, MD.

[27] AOAC, Association of Official Analytical Chemists, in Official Methods of Analysis: Official Method for Protein. Method No. 920.87. 1995: Washington DC.

[28] AOAC, Association of Official Analytical Chemists, in Official methods of analysis: Proximate Analysis and Calculations Crude Fiber. Method No 978.10. 2006: Gaithersburg, MD.

[29] U. Osuna-Martínez, J. Reyes-Esparza, L. Rodríguez-Fragoso, and U. Osuna-Martínez, "Cactus (Opuntia ficus-indica): a review on its antioxidants properties and potential pharmacological use in chronic diseases," Natural Products Chemistry \& Research, 2014.
[30] B. Altunakar, S. Sahin, and G. Sumnu, "Functionality of batters containing different starch types for deep-fat frying of chicken nuggets," European Food Research and Technology, vol. 218, no. 4, pp. 318-322, 2004.

[31] A. Heredia, M. L. Castelló, A. Argüelles, and A. Andrés, "Evolution of mechanical and optical properties of French fries obtained by hot air-frying," LWT- Food Science and Technology, vol. 57, no. 2, pp. 755-760, 2014.

[32] P. J. Fellows, Food processing technology: principles and practice, Elsevier, 2009.

[33] M. Taniwaki, N. Sakurai, and H. Kato, "Texture measurement of potato chips using a novel analysis technique for acoustic vibration measurements," Food Research International, vol. 43, no. 3, pp. 814-818, 2010.

[34] J. Chen, C. Karlsson, and M. Povey, "Acoustic envelope detector for crispness assessment of biscuits," Journal of Texture Studies, vol. 36, no. 2, pp. 139-156, 2005.

[35] A. Salvador, P. Varela, T. Sanz, and S. M. Fiszman, "Understanding potato chips crispy texture by simultaneous fracture and acoustic measurements, and sensory analysis," LWT_Food Science and Technology, vol. 42, no. 3, pp. 763-767, 2009.

[36] A. Kita, G. Lisińska, and G. Gołubowska, "The effects of oils and frying temperatures on the texture and fat content of potato crisps," Food Chemistry, vol. 102, no. 1, pp. 1-5, 2007.

[37] A. Kita, G. Lisińska, and M. Powolny, "The influence of frying medium degradation on fat uptake and texture of French fries," Journal of the Science of Food and Agriculture, vol. 85, no. 7, pp. 1113-1118, 2005.

[38] E. Pacheco-Delahaye, "Evaluación nutricional de hojuelas fritas y estudio de la digestibilidad del almidón de plátano verde (Musa spp.)," Rev. Fac. Agron, vol. 28, pp. 42-48, 2002.

[39] F. Pedreschi and P. Moyano, "Oil uptake and texture development in fried potato slices," Journal of Food Engineering, vol. 70, no. 4, pp. 557-563, 2005.

[40] K. N. van Koerten, M. A. I. Schutyser, D. Somsen, and R. M. Boom, "Crust morphology and crispness development during deep-fat frying of potato," Food Research International, vol. 78, pp. 336-342, 2015.

[41] J. Rahimi, P. Adewale, M. Ngadi, K. Agyare, and B. Koehler, "Changes in the textural and thermal properties of batter coated fried potato strips during post frying holding," Food and Bioproducts Processing, vol. 102, pp. 136-143, 2017.

[42] S. Mazurek, R. Szostak, and A. Kita, "Application of infrared reflection and Raman spectroscopy for quantitative determination of fat in potato chips," Journal of Molecular Structure, vol. 1126, pp. 213-218, 2016.

[43] A. O. Oladejo, H. Ma, W. Qu et al., "Effects of ultrasound pretreatments on the kinetics of moisture loss and oil uptake during deep fat frying of sweet potato (Ipomea batatas)," Innovative Food Science and Emerging Technologies, vol. 43, pp. 7-17, 2017.

[44] M. C. Moreno, C. A. Brown, and P. Bouchon, "Effect of food surface roughness on oil uptake by deep-fat fried products," Journal of Food Engineering, vol. 101, no. 2, pp. 179-186, 2010.

[45] J. Yang, A. Martin, S. Richardson, and C.-H. Wu, "Microstructure investigation and its effects on moisture sorption in fried potato chips," Journal of Food Engineering, vol. 214, pp. 117-128, 2017.

[46] N. Z. Ngobese, T. S. Workneh, and M. Siwela, "Effect of low-temperature long-time and high-temperature short-time blanching and frying treatments on the French fry quality of six 
Irish potato cultivars," Journal of Food Science and Technology, vol. 54, no. 2, pp. 507-517, 2017.

[47] T. M. Millin, I. G. Medina-Meza, B. C. Walters, K. C. Huber, B. A. Rasco, and G. M. Ganjyal, "Frying Oil Temperature: Impact on Physical and Structural Properties of French Fries During the Par and Finish Frying Processes," Food and Bioprocess Technology, vol. 9, no. 12, pp. 2080-2091, 2016.

[48] E. Karacabey, M. S. Turan, Ş. G. Özçelik, C. Baltacıoğlu, and E. Küçüköner, "Optimisation of pre-drying and deep-fat-frying conditions for production of low-fat fried carrot slices," Journal of the Science of Food and Agriculture, vol. 96, no. 13, pp. 46034612, 2016.

[49] E. J. Pinthus, P. Weinberg, and I. S. Saguy, "Oil Uptake in Deep Fat Frying as Affected by Porosity," Journal of Food Science, vol. 60, no. 4, pp. 767-769, 1995.

[50] N. Pak, "Análisis de fibra dietética," in Produccion y manejo de datos de composicion quimica de alimentos en nutricion, $\mathrm{C}$. Moron, I. Zacarias, and., and S. d. Pablo, Eds., FAO. Dirección de Alimentación y Nutrició, Santiago, 1997.

[51] J. L. Slavin, "Dietary fiber: classification, chemical analyses, and food sources.," Journal of the Academy of Nutrition and Dietetics, vol. 87, no. 9, pp. 1164-1171, 1987. 


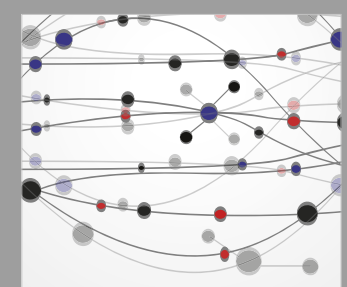

The Scientific World Journal
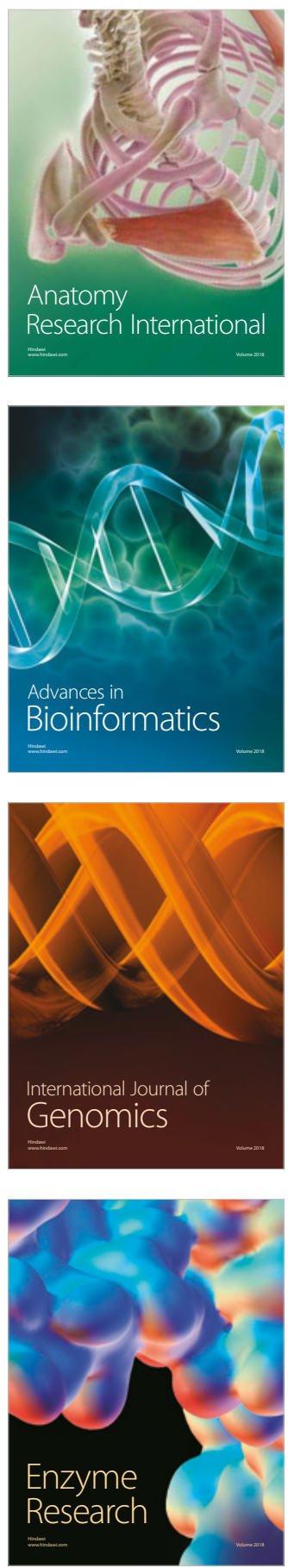
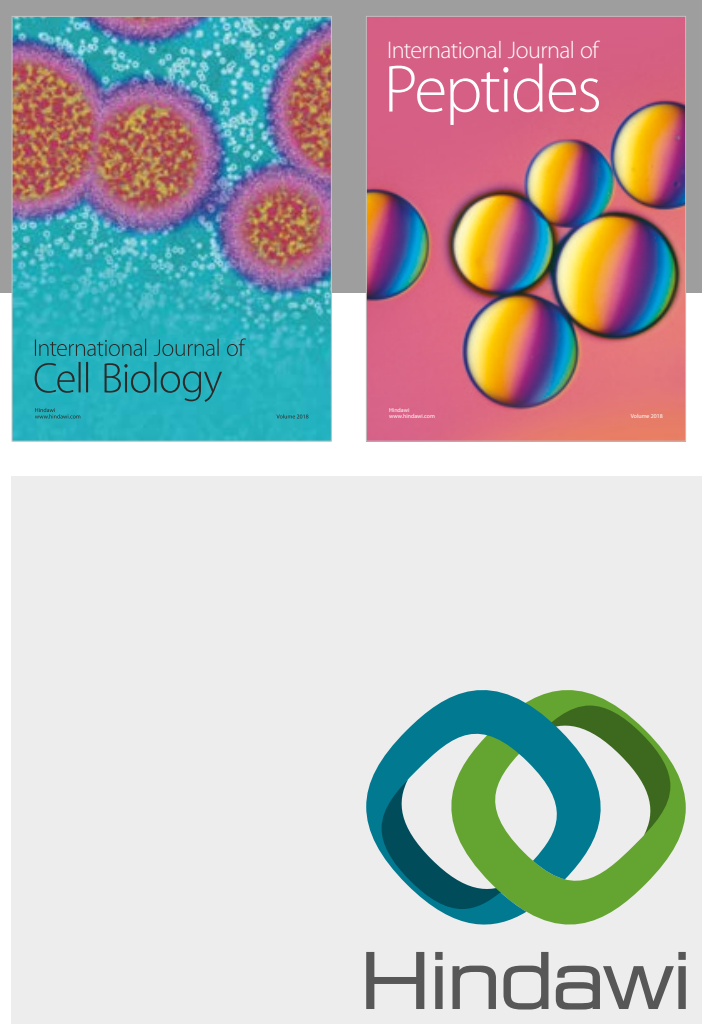

Submit your manuscripts at

www.hindawi.com
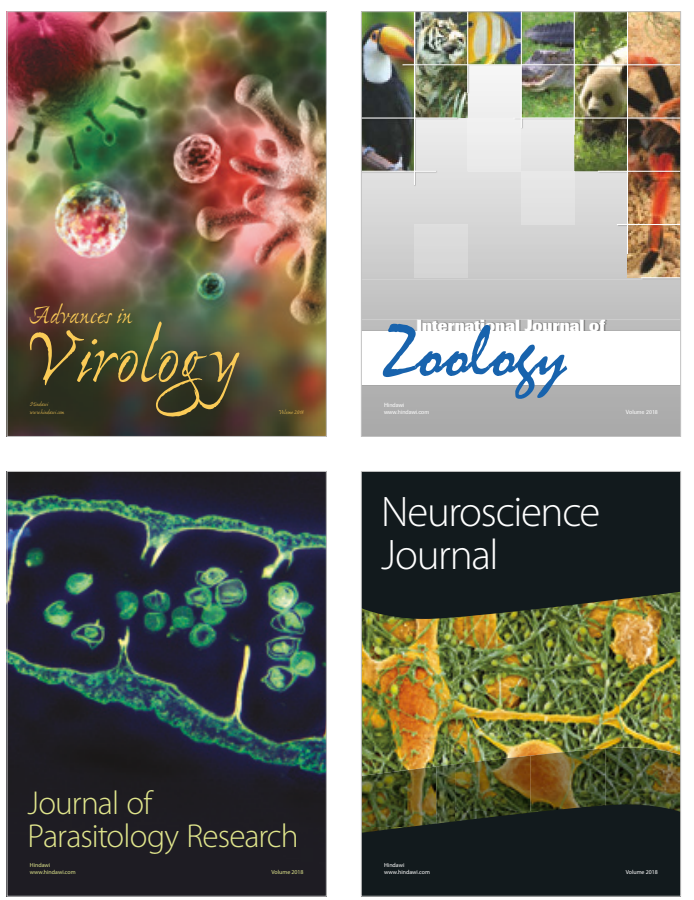
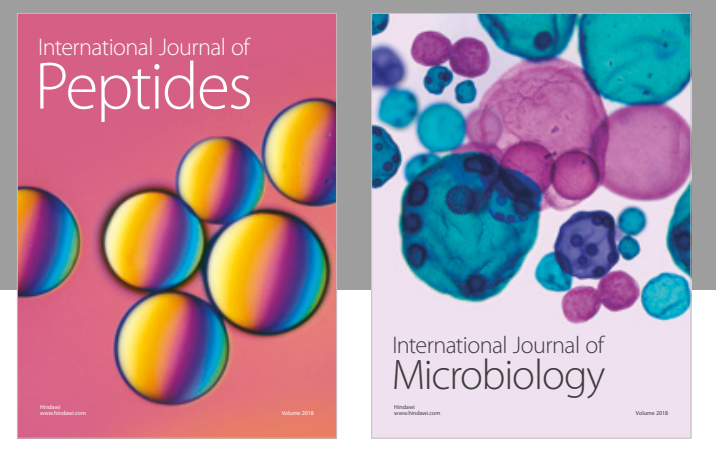

nternational Journal of Microbiology
Journal of
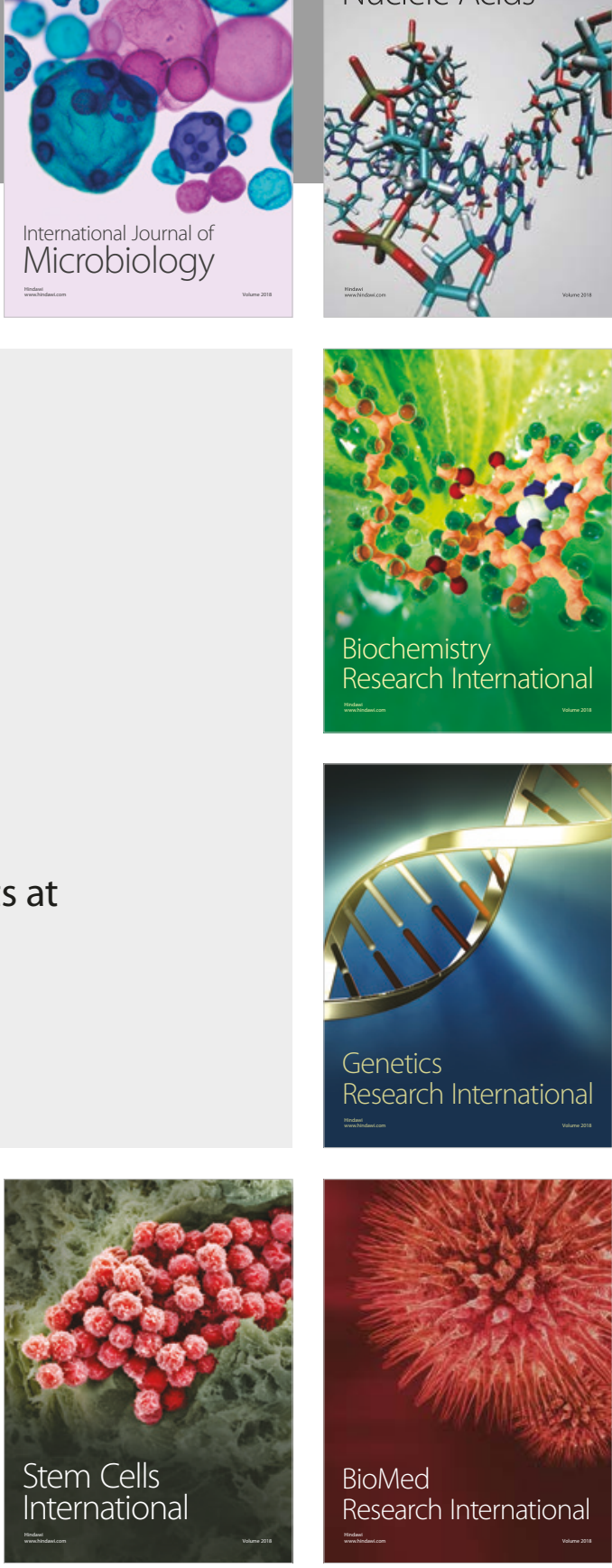
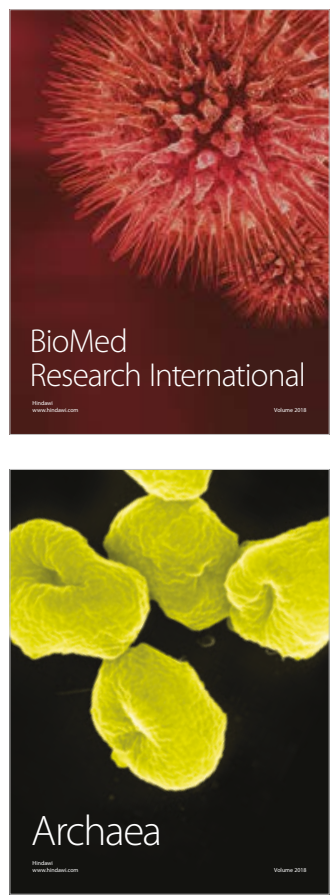